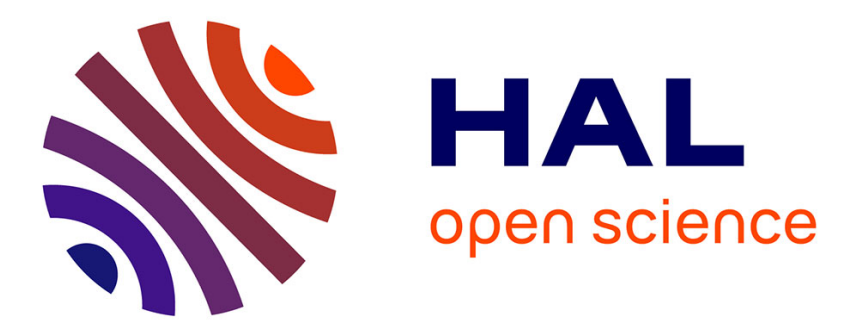

\title{
Attenuated brain responses to speech sounds in moderate preterm infants at term age
}

Clément François, Antoni Rodriguez-fornells, Maria Teixidó, Thaïs Agut, Laura Bosch

\section{- To cite this version:}

Clément François, Antoni Rodriguez-fornells, Maria Teixidó, Thaïs Agut, Laura Bosch. Attenuated brain responses to speech sounds in moderate preterm infants at term age. Developmental Science, 2021, 24 (1), 10.1111/desc.12990 . hal-02881530

\section{HAL Id: hal-02881530 \\ https://hal.science/hal-02881530}

Submitted on 25 Jun 2020

HAL is a multi-disciplinary open access archive for the deposit and dissemination of scientific research documents, whether they are published or not. The documents may come from teaching and research institutions in France or abroad, or from public or private research centers.
L'archive ouverte pluridisciplinaire HAL, est destinée au dépôt et à la diffusion de documents scientifiques de niveau recherche, publiés ou non, émanant des établissements d'enseignement et de recherche français ou étrangers, des laboratoires publics ou privés. 
Clément François $^{1^{*}}$, Antoni Rodriguez-Fornells ${ }^{2,3,4}$, Maria Teixidó ${ }^{3}$, Thaïs Agut ${ }^{5,6}$, Laura Bosch $3,6,7$

\footnotetext{
${ }^{1}$ Aix-Marseille University, CNRS, LPL, Aix-en-Provence, France

${ }^{2}$ Cognition and Brain Plasticity Group [Bellvitge Biomedical Research Institute-]

IDIBELL, L'Hospitalet de Llobregat, Barcelona, Spain

${ }^{3}$ Department of Cognition, Development and Educational Psychology, University of Barcelona, Barcelona, Spain

${ }^{4}$ Catalan Institution for Research and Advanced Studies, ICREA, Barcelona, Spain

${ }^{5}$ Department of Neonatology, Hospital Sant Joan de Déu, Barcelona, Spain

${ }^{6}$ Institut de Recerca Sant Joan de Déu, Barcelona, Spain

${ }^{7}$ Institute of Neurosciences (UBNeuro), University of Barcelona, Barcelona, Spain
}

*Corresponding author:

Clément François, Laboratoire Parole et Langage, Aix-Marseille University, CNRS, UMR7309, Aix-en-Provence, France.

Email: clement.francois@univ-amu.fr 


\begin{abstract}
Recent findings have revealed that very preterm neonates already show the typical brain responses to place of articulation changes in stop consonants, but data on their sensitivity to other types of phonetic changes remains scarce. Here, we examined the impact of 7-8 weeks of extra-uterine life on the automatic processing of syllables in 20 healthy moderate preterm infants (mean gestational age at birth 33 weeks) matched in maturational age with 20 fullterm neonates, thus differing in their previous auditory experience. This design allows elucidating the contribution of extra-uterine auditory experience in the immature brain on the encoding of linguistically relevant speech features. Specifically, we collected brain responses to natural $\mathrm{CV}$ syllables differing in three dimensions using a multi-feature mismatch paradigm, with the syllable /ba/ as the standard and three deviants: a pitch change, a vowel change to /bo/, and a consonant Voice Onset Time (VOT) change to /pa/. No significant between-group differences were found for pitch and consonant VOT deviants. However, moderate preterm infants showed attenuated responses to vowel deviants compared to fullterms. These results suggest that moderate preterm infants' limited experience with low-pass filtered speech prenatally can hinder vowel change detection and that exposure to natural speech after birth does not seem to contribute to improve this capacity. These data are in line with recent evidence suggesting a sequential development of a hierarchical functional architecture of speech processing that is highly sensitive to early auditory experience.
\end{abstract}




\section{INTRODUCTION}

According to the World Health Organization, almost 15 million babies were born preterm all around the world in 2010 (Blencowe et al., 2012). Preterm birth can impact language and cognitive development. Around $25-30 \%$ of very preterm infants (i.e. born between 28- and 32-weeks gestational age -wGA-) show delays in language acquisition that can be observed already in their second year of life (Sansavini et al., 2010). Premature infants are also at risk for cognitive delays with immaturity levels at birth being linked to cognitive outcomes at school age (Bhutta et al., 2002). In the speech perception domain, developmental timing differences between healthy full-terms (FT) and preterms have also been reported in early language discrimination skills, word segmentation, and lexical stress differentiation in very preterm infants (Peña et al., 2010; Bosch, 2011; Herold et al., 2008, respectively).

Previous results on the impact of preterm birth on the brain responses to different types of speech sounds are still scarce and not clear-cut. While a few days after birth, very preterm neonates exhibit discriminative brain responses for a phonetic change in place of articulation of a consonant, (ba vs. ga), (Mahmoudzadeh et al., 2013, 2017; Key et al., 2012). Later in development, very preterm infants, tested between 3 and 9 months of age, may present delayed brain responses to a different place of articulation consonant contrast (ba vs. da) (Paquette et al., 2015; Peña et al., 2012). The latter results are more in line with previous neuroimaging studies showing an atypical organization of the language network in preterm infants (Mürner-Lavanchy et al., 2014; Liu et al., 2010; Baldoli et al., 2015). However, these studies exclusively focused on very preterm infants, born at or before 32-wkGA, and very little is known about moderate preterm neonates born between 32- and 36-wGA and their capacity to discriminate different types of speech contrasts.

The perception of a voicing contrast in stop consonants relies on a fine-grained temporal analysis which is related to changes in the voice onset time parameter (VOT), i.e., the interval between the noise-burst produced at consonant release and the onset of the waveform periodicity associated with vocal cord vibration (Lisker \& Abramson, 1967). On the other hand, the perception of a vowel change is based on spectral differences conveyed by the distribution of the frequencies of the first few formants (Hillenbrand \& Gayvert, 1993). Because the womb strongly degrades and filters the fine-grained temporal information necessary to identify the stop consonants contained in the speech signal (Griffiths et al., 1994; Lecanuet \& Schaal, 1996), preterm babies may benefit from the early and rich stimulation received from the outside world to successfully detect a consonant change (Key et al., 2012; Therien et al., 2004). But at the same time, an early experience with the broad spectrum of frequencies of speech and especially the high frequency noise in the neonatal units may have a negative impact on the functioning of the speech network (Lahav \& Skoe, 2014). In other words, exposure to low-pass filtered sounds and speech during intrauterine life, as typically 
experienced by full term infants, plays not only a protective role for hearing development, but it may also constrain the auditory system in favor of prosody-based information reflected by the sequential acquisition of specific prosodic and phonetic speech features (Ragó et al., 2014). Preterm birth may, thus, disrupt the developmental timing in the processing of different speech properties relevant to language learning.

To better characterize the influence of an early exposure to the broad spectrum of frequencies of the language on the automatic processing of syllables in infants born moderately preterm, we recorded the brain responses to changes in three different speech dimensions in 20 healthy FT and 20 healthy moderate preterm infants (PTm) tested at term age. Importantly, compared to FT, preterm infants had had a different auditory experience in the 7-8 weeks before testing. We used a largely validated multi-feature mismatch negativity (MMN) paradigm (Näätänen et al. 2004; Partanen et al., 2013) with the syllable /ba/ as standard and three deviants on the following dimensions: pitch (F0 change), vowel quality (spectral change in formant frequency values), and VOT difference (a consonant change based on the voicing dimension). This paradigm allowed us collecting the mismatch response (MMR) indicating cortical processes of automatic memory-based auditory change detection or prediction error (Näätanen et al., 2007; Friston 2005; Gagnepain et al., 2012). The MMR can be elicited by low level (acoustic) changes in pitch, duration, voice-onset time or vowel type in neonates and children (Cheour et al., 1998; Chobert et al., 2012a, 2012b; DehaeneLambertz, 2002; Partanen et al., 2013; Rivera-Gaxiola et al., 2005). Importantly, the MMR can be also obtained in multi-feature MMN paradigms involving different types of deviants with different probabilities of occurrences or containing abstract rules determining regularities between non-consecutive linguistic and non-linguistic stimuli (Mueller et al., 2012; François et al., 2017), so the MMR can also reflect the ability to generate higher-order predictions (Näätänen et al., 2004; Vidal et al., 2019). The analysis and comparison of brain responses to VOT and vowel changes should reveal which speech dimension is most affected by differences in the nature of the speech stimulation experienced in the months preceding the testing (i.e. low-pass filtered speech vs. broad spectrum natural speech in the outside world). Considering previous studies on the perception of a place of articulation consonant contrast (ba/ga) and a male/female voice change in very early preterms, showing clear neural discrimination of the phonetic contrast but attenuated neural responses to voice changes (Mahmoudzadeh et al., 2013, 2017), we expected PTm infants evaluated at term age to show equivalent (or attenuated) MMR to pitch and vowel changes when compared to FTs. For VOT deviants, two possible outcomes were possible. If the early exposure to the broad spectrum of frequencies before term age has a positive impact leading to better processing of fine-grained temporal cues, then we could expect PTm infants to exhibit an enhanced MMR 
to VOT deviants as compared to FT neonates. Alternatively, if this early exposure has a negative impact, PTms should exhibit an attenuated MMR as compared to FTs.

\section{METHODS}

\section{Participants}

A total of 40 healthy babies were enrolled in this experiment with 20 healthy fullterm neonates (12 males; mean gestational age [GA] at birth $=39.6$ weeks GA [38.2 - 41.4]; mean birth weight $=3122 \mathrm{~g}[2210-4420]$; Apgar-5 $>9$; mean postnatal age at test $=2.8$ days \pm 0.7 ; mean maturational age at test (gestational age at birth + postnatal age) $=40.1$ weeks [38.2 - 42]) and 20 healthy moderate preterm neonates (19 males; mean GA= 33 wGA [32.2 35.6]; mean birth weight $=1837 \mathrm{~g}[1520-2400]$; Apgar $-5>9$; mean postnatal age at test $=$ 51 days \pm 15 ; mean maturational age at test $=40.1$ weeks [39 -42.3 ]; see Figure 1 for an illustration of the design). The mean postnatal age ( $\mathrm{t}_{19}=22.57 ; P<.0001$, two-tailed), the mean GA at birth $\left(\mathrm{t}_{19}=18.90 ; P<.0001\right.$, two-tailed $)$ and the mean birth weight $\left(\mathrm{t}_{19}=9.303 ; P<.0001\right.$, two-tailed) were significantly different between the two groups. Importantly however, the mean maturational age at test was not significantly different between the two groups ( $\mathrm{t}_{19}=0.27 ; P=.78$, two-tailed). All the newborns were recruited and tested at the maternity ward. Parents were informed and signed a consent form at the beginning of the experimental session. The hospital ethics committee approved our procedures and protocols (CEIC-PIC-6913). All neonates had normal hearing from the universal screening test (AABR, Automated Auditory Brainstem Response) and normal examination made by a neonatologist at the delivery ward.

\section{Stimuli}

Stimuli were natural syllables with a Consonant-Vowel (CV) structure recorded from a female Spanish speaker. The standard stimulus /ba/ had a fundamental frequency (F0) of $180 \mathrm{~Hz}$, vowel duration of $213 \mathrm{~ms}$ and a VOT of $-130 \mathrm{~ms}$ with a total duration of the stimulus of $340 \mathrm{~ms}$ (see Figure 1). For pitch deviant, the vowel identity and the VOT were the same as for the standard but the F0 of the vowel was increased by $50 \%$ using the software Audition $(270 \mathrm{~Hz})$. For vowel deviant, we recorded a /bo/ syllable and used Praat to excise the vowel and replace the original vowel /a/ in such a way that vowel duration and VOT were the same as for the Standard. Therefore, the onset of vowel change occurred at $127 \mathrm{~ms}$ after syllable onset. The VOT deviant /pa/ had a F0 of $180 \mathrm{~Hz}$, a vowel duration of $213 \mathrm{~ms}$ for a total syllabic duration of $233 \mathrm{~ms}$ and a Voice Onset Time (VOT) of -20 ms. 
(a) Experimental design

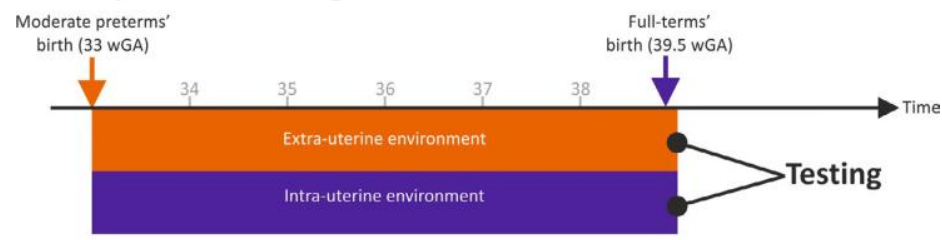

(b) Stimuli (Multi-feature MMN)

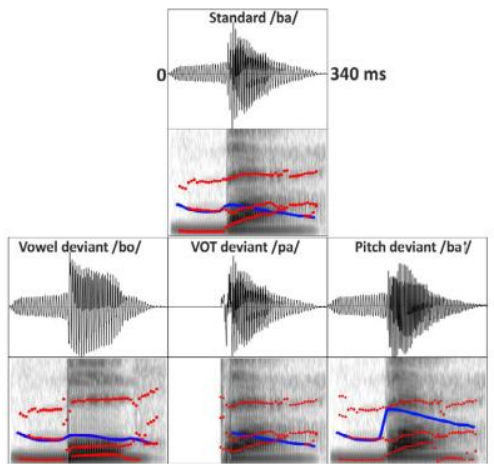

Figure 1: A) Experimental design used in the present study. B) Illustration of the four CV syllables used in the multi-feature MMN paradigm with both the sound wave and spectrogram. The red dots depict the four first formants and the purple trace depicts the fundamental frequency of each stimulus with the CV syllable /ba/ used as a standard, the /ba $\uparrow /$ used as deviant in pitch, the /bo/ used as deviant in vowel quality, and the /pa/ used as deviant in VOT. The four syllables had a duration of $340 \mathrm{~ms}$. The onset of vowel change occurred at $127 \mathrm{~ms}$ after syllable onset.

\section{Procedure}

The entire recording session took place directly in the room of the hospital and at least one of the parents was present during the session. Infants were tested while sleeping on their cribs. Stimuli were played at a 75-dB volume through a loudspeaker placed at about $1 \mathrm{~m}$ from the infant's crib in a single block that lasted $12.2 \mathrm{~min}$. A total of 704 stimuli were used with 3 deviants ( 72 for each of the 3 deviant types; $10 \%$ probability for each deviant). Pitch, vowel quality, and VOT deviants were randomly presented within the auditory sequence with a Sound Onset Asynchrony (SOA) of 600 ms synchronized with vowel onset.

\section{EEG data acquisition and processing}

The EEG was recorded from 16 scalp electrodes (Biosemi ActiveTwo system, Amsterdam University) located at standard positions (International 10/20 system sites: Fp1, Fp2, F3, F4, T7, C3, C4, T8, P3, P4, O1, O2, Fz, Cz, Pz, and Oz). The EEG was amplified by Biosemi amplifiers with a band-pass of $0-102.4 \mathrm{~Hz}$ and was digitized at $250 \mathrm{~Hz}$. The EEG data were re-referenced offline to the algebraic average of the mastoids. Those data were offline filtered from 1 to $20 \mathrm{~Hz}$, and epochs containing external artifacts exceeding $\pm 150 \mu \mathrm{V}$ were removed, as done in previous studies in infants (Martynova et al., 2003; Kostilainen et al., 2018; Paquette et al., 2015; Kushnerenko et al., 2007). EEG data were split into epochs from $-100 \mathrm{~ms}$ to $600 \mathrm{~ms}$ from stimulus onset and baseline-corrected. The first ten standards were systematically removed from the analyses. 


\section{EEG data analysis}

Based on previous literature showing a frontal distribution of the MMN (Mahmoudzadeh et al., 2017; Suppiej et al., 2010), we analyzed the averaged brain responses over a frontal region of interest (ROI) that included 5 frontal electrodes (Fp1/2, F3/Fz/F4). This was done to increase the signal to noise ratio and to simplify the analyses.

We first performed point-by-point $t$-tests comparing deviants and standards for each condition and in each group. As a second step, and to study group differences of habituation/adaptation in response to standards, we performed point-by-point $t$-tests comparing responses to standards across groups. The corresponding significant temporal clusters were corrected for multiple comparisons using the Bonferroni-Holm FDR correction method to avoid false-positives (Benjamini \& Hochberg, 1996).

Finally, we studied differential MMN responses across groups by comparing the mean amplitude in $20 \mathrm{~ms}$ time-windows centered on the peak difference waveforms (deviant minus standard) obtained in each condition as done in previous studies (Zhang et al., 2011; Háden et al., 2009; Otte et al., 2013). The peaks were visually identified as the most negative or positive peak in the all infants grand-average (collapsing the two groups of infants) difference waveform in each condition (Pitch: $200 \mathrm{~ms}$; Vowel: $236 \mathrm{~ms}$, VOT: 84, and $432 \mathrm{~ms}$, see Figure 2). The mean amplitudes were compared using t-tests for independent samples.

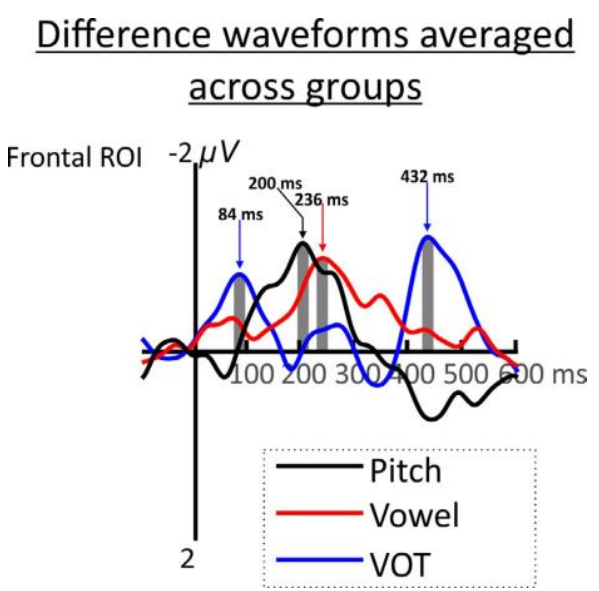

Figure 2: All infants $(\mathrm{N}=40)$ grand average difference waveforms (deviant - standard) over the frontal ROI (averaged of 5 frontal electrodes, see Methods) for the three conditions (Black: Pitch, Red: Vowel, and Blue: VOT deviants). The grey areas show the peak-centered $20 \mathrm{~ms}$ time windows selected for between-group comparisons.

\section{RESULTS}

Average ERPs to standard and deviant stimuli are shown separately for the two groups in Figure 3. As can be seen, most of the deviants elicited MMRs in the two groups, thus confirming the usability of the multi-feature MMN paradigm in neonates (Partanen et al., 
2013). In FT, pitch and vowel deviants elicited negative frontal brain responses peaking around $200 \mathrm{~ms}$. However, the VOT deviant, based on a fast temporal cue, elicited a different pattern of response with an early negativity followed by a late negativity between 400 and 500 ms (Kushnerenko et al., 2002; Dehaene-Lambertz \& Dehaene, 1994; Čeponienė et al., 2004). Results of the point-by-point t-tests revealed significant differences between standard and deviants between 180 and $200 \mathrm{~ms}$ for pitch deviants and between 200 and $272 \mathrm{~ms}$ for vowel deviants. However, despite visible effects on the waveforms in the VOT condition, no significant effects were found.

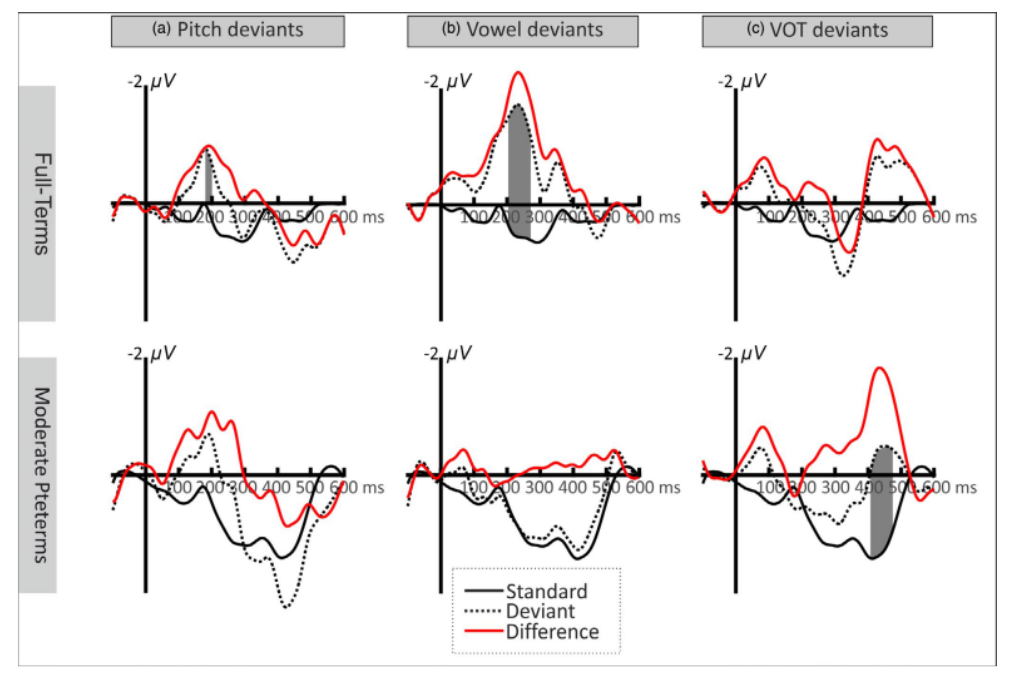

Figure 3. Grand average ERPs over the frontal ROI (averaged of 5 frontal electrodes, see Methods) to standards (black), deviants (dotted lines), and to the difference waveform (Deviant - Standard, red) separately for the two groups of infants (top: Full-terms; bottom: Moderate preterms) and for each deviant condition (A: Pitch; B: Vowel; $\mathrm{C}$ : VOT). The grey areas show point-by-point significant differences between standard and deviant $(P<.05$, FDRcorrected at the cluster level).

In PTm, the patterns of response for pitch deviants were very similar to those observed in FT, however, results of the point-by-point analysis failed to reveal significant differences between standards and deviants, probably due to a high inter-individual variability in this group. For vowel deviants, no significant difference between standard and deviants was found. However, for VOT deviants, a significant difference was observed between 400 and $480 \mathrm{~ms}$ with a larger negativity for deviants than for standards.

To study habituation/adaptation processes, we compared ERPs to standards between the two groups. Interestingly, PTm presented a larger late positivity compared to FTs. Results of point-by-point t-tests revealed significant differences between 324 and $484 \mathrm{~ms}$ (see Figure 4) suggesting that our group of moderate preterms may present impaired habituation/adaptation processes. 


\section{ERPs to standards}

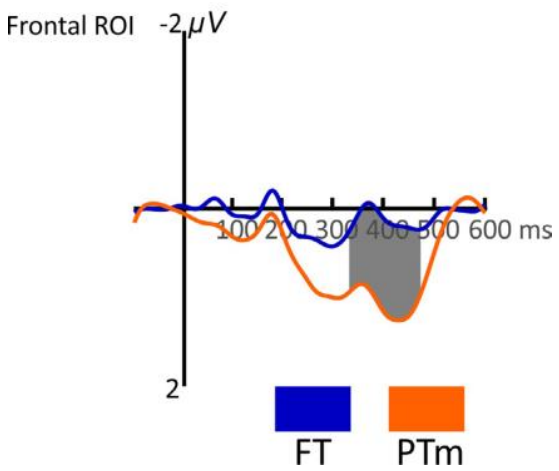

Figure 4. Grand average ERPs to standards for the two groups of infants over the frontal ROI (Blue: Full-terms, Orange: moderate Preterms). The grey areas show significant point-by-point differences between the two groups $(P<.05$, FDR-corrected at the cluster level).

Finally, we studied the differential MMRs across groups by directly comparing the difference waveforms separately for each condition (see Figure 5). For pitch deviants, the comparison of the two groups in the $20 \mathrm{~ms}$ time-window failed to reach significance (FT: -1.1 $\mu \mathrm{V}$; PTm: $-1.1 \mu \mathrm{V} ; t(38)=.09 ; P=.93)$. For vowel changes, we found a significantly larger MMR in FT $(-2 \mu \mathrm{V})$ than in PTm $[0.04 \mu \mathrm{V} ; t(38)=-2.34 ; P=.02]$. For VOT deviants, the comparisons of the two groups were not significant neither for the early (FT: $-0.73 \mu \mathrm{V}$; PTm: $-0.88 \mu \mathrm{V} ; t(38)=.27 ; P=.78$ ) nor for the late negativity (FT: $-0.74 \mu \mathrm{V} ;$ PTm: $-1.63 \mu \mathrm{V}$; $\mathrm{t}(38)=1.09 ; P=.28)$.

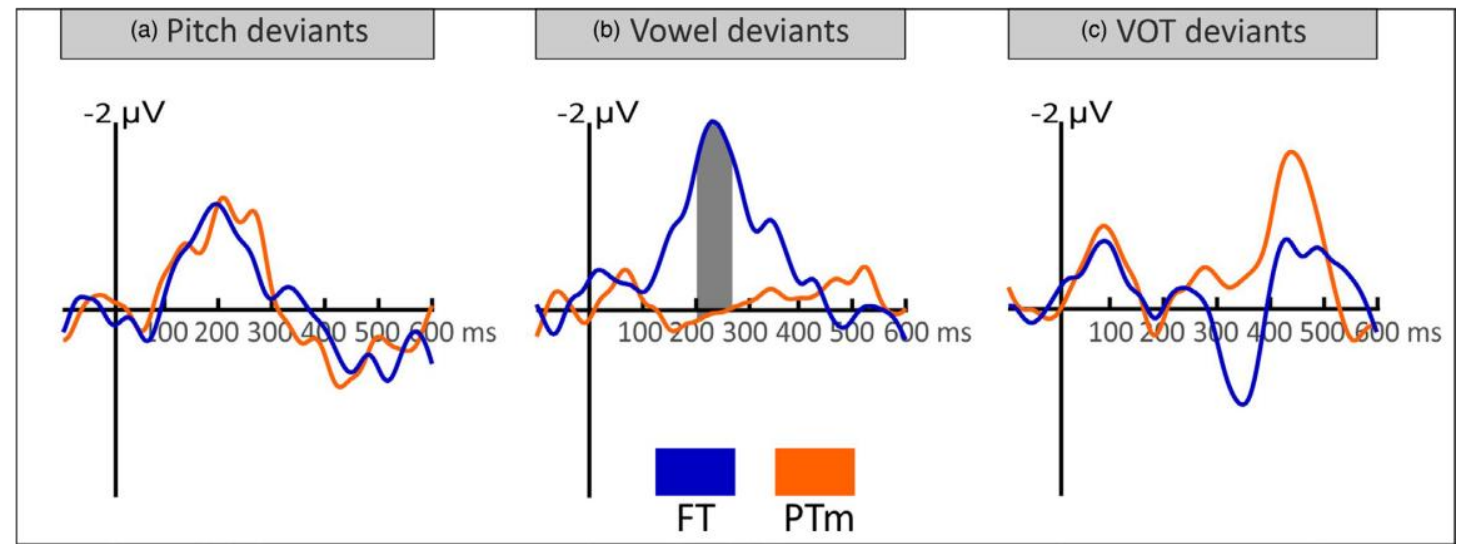

Figure 5. Grand average difference waveforms (deviant - standard) for the two groups of infants (Blue: Fullterms, Orange: moderate Preterms) over the frontal ROI separately for each condition (A: Pitch, B: Vowel, C: VOT). The grey areas show significant point-by-point significant differences between standard and deviant $(P<.05$, FDR-corrected at the cluster level).

\section{DISCUSSION}

The present study brings new evidence on the role that early experience with natural language has on the processing of speech sounds. We compared 20 healthy moderate preterm infants matched in maturational age with 20 full-term neonates, thus differing in their 
previous auditory experience. We used a multi-feature MMN paradigm with deviants on three dimensions: pitch (F0), vowel quality (change in formant frequency values), and consonant VOT difference. We found an impact of 7-8 weeks of exposure to natural speech after moderately preterm birth on brain sensitivity to a vowel quality change. These results have strong implications for refining our knowledge on the early functional development of the auditory pathway supporting speech processing and on the impact of experience-dependent mechanisms during early development.

Regarding the response to a pitch change, no significant between-group differences were found even though only FTs presented a significant MMR (see Figure 3). This result suggests a high inter-individual variability in the processing of pitch changes in both groups. Indeed, both groups may have presented a relatively small response, but in the case of FTs, due to random effects, the group average passes the statistical threshold while for the PTm group it does not. Such high variability could be due to inaccurate time locking of the inferior colliculus activity or to non-optimally functioning connections between the brainstem and the auditory cortex.

Contrary to the negative MMR elicited by the pitch and vowel deviants, the brain responses to VOT deviants elicited an early frontal negativity followed by a late negativity (see Figure 2 and Figure 5). This pattern of brain responses is in line with previous results from older infants but also from newborns who show similar brain responses to consonant changes (Dehaene-Lambertz \& Dehaene, 1994, Dehaene-Lambertz \& Baillet, 1998; DehaeneLambertz \& Peña, 2001; Maitre et al., 2013), as well as to white noise deviants in a sequence of harmonic tones (Kushnerenko et al., 2007; 2013). However, no between group differences and no differences at the level of the early negativity were observed, pointing to difficult avenues in the study of VOT changes in newborns.

Mahmoudzadeh and colleagues (2017) tested very pre-term neonates few days after birth using a two-deviant syllable discrimination task involving a voice change (male vs. female) and a change in place of articulation (/ba/ vs. /ga/). Results showed clear MMRs for consonant changes but no response for the deviants that relied on steady-state differences as those required for voice processing (Zatorre \& Belin, 2001). Here, preterms were assessed at term age (i.e. postnatal age corrected for gestation) and had been exposed to natural language for 7-8 weeks on average, time during which they could hear the broad spectrum of speech frequencies and prosody. Compared to FTs, the group of PTm showed attenuated MMRs to a vowel change. This result extends previous behavioural and electrophysiological evidence for differences in preterms' vowel processing compared to healthy FTs (Figueras \& Bosch, 2010; Jansson-Verkasalo et al., 2010). However, the results in the VOT condition were not clear-cut enough to claim that the two groups were differing only in the processing of vowels. 
Premature birth may thus alter the functional maturation of the speech network by at least impacting the processing of steady-state features of speech. The present results support the idea that normal development facilitates the maturation of brain functions in a manner that is optimal for the still-developing human sensory system (Werker \& Hensch, 2015; Ragó et al., 2014).

Interestingly, despite no group differences in the difference waveforms, the comparison of standards and VOT deviants showed significant differences at the level of the late negativity in the PTm group only. This may suggest enhanced predictive sound sequence processing mechanisms fostered by early exposure to the extra-uterine environment. The ability to generate predictions of upcoming stimuli at different hierarchical levels to enhance their processing is an important aspect of the human auditory system (Wacongne et al., 2011; Friston 2005; Phillips et al., 2016). In the context of speech, predictive coding would lay on the generation of continuous sensory predictions based on the linguistic regularities of the environment (Gagnepain et al., 2012; Bendixen et al., 2012) to facilitate speech perception and comprehension in adults (Arnal \& Giraud, 2012; Bendixen et al., 2009, 2014; Grisoni et al., 2019), but also novel word learning in infants and toddlers (Ylinen et al., 2016; 2017; Benitez \& Saffran, 2018). The most common way to study auditory predictive coding abilities involves the Oddball paradigm which consists in the presentation of a sequence of repeated stimuli interleaved with deviants randomly presented. The ability to generate higher-order predictions is also largely studied with other types of Oddball paradigms such as the multifeature MMN paradigm involving different types of deviants with different probability of occurrences or containing abstract rules determining regularities between non-consecutive stimuli (Näätänen et al., 2004; Vidal et al., 2019). Human healthy full-term neonates already possess functionally active auditory brain networks capable of predictive processes for speech and non-speech stimuli (Háden et al., 2015; François et al., 2017). Previous studies have also revealed an influence of the context on the MMR to pure tone pitch changes suggesting that context-dependent auditory processing is present in healthy FTs (Háden et al., 2013, 2016). It also seems that very premature birth can negatively impact this type of predictive processing (Emberson et al., 2017; Boldin et al., 2018). However, it can also be considered that an early exposure to speech in the extra-uterine environment might positively impact the development of predictive context-dependent processing. Besides, it is important to keep in mind that the FT and PTm comparison of ERPs to standards revealed a larger late positivity in the PTm group (see Figure 4) and that this difference falls in the same latency range as the late negativity in the VOT condition. This larger positivity may reflect impaired habituation/adaptation to repeated stimuli. Further studies are needed to specify the role of early exposure on habituation/adaptation and predictive coding abilities with more controlled stimuli. 
Our study presents some limitations related to the design and the stimuli used. First, we could only perform a single comparison based on matched maturational age but not based on chronological (postnatal) age. In order to better determine the effect of exposure to natural, non-filtered speech on the brain sensitivity to phonetic changes, at different postnatal ages, future studies should compare PTm and FT (i) when matched in postnatal age (i.e. both groups infants tested at 2 days after birth) or (ii) when matched in the amount of exposure to non-filtered natural speech (i.e. both groups of infants tested after 7-8 weeks of postnatal exposure to the extra-uterine language environment). Second, we used natural speech stimuli which are less controlled than semi-synthetic or artificial syllables allowing a perfect control of the acoustic parameters. Further studies will have to address these issues to disentangle the role of pre-programmed as opposed to experience-dependent factors in development with more controlled stimuli. Finally, the relatively small number of infants included in the present study led us to perform our analyses on the averaged responses over a region of interest; further studies with a better signal to noise ratio will allow specifying possible topographical differences between FTs and PTm infants.

In summary, our results suggest that 7-8 weeks of extra-uterine exposure to speech may have a negative impact on the processing of vowel quality changes in healthy moderate preterm infants tested at term age. These results favour the view of a functional architecture of the speech networks relying on a dual processing stream for fast and steady-state features of speech. Considering the interplay between early experience and built-in capacities, further studies using longitudinal designs will contribute to shed more light on the developmental changes occurring during the first year of life in moderate preterm infants.

\section{ACKNOWLEDGEMENTS}

We thank all the families and their babies for participating in the study. We also thank the medical staff from the maternal care unit in Sant Joan de Déu Hospital. We thank D. Cucurell and J. Solé for their help in different steps of the study. This research has been supported by a SLT002/16/00390 grant, funded by the Department of Health of the Generalitat de Catalunya by the call "Acció instrumental d'incorporació de científics i tecnòlegs", a grant from FYSSEN foundation (post-doctoral grant), Spanish MINECO projects (PSI2015-69132P) to CF, and (PSI2014-55105P) to LB, as well as Spanish MICINN project (PGC2018-097487-B$100)$ to LB. The data that support the findings of this study are available on reasonable request from the corresponding author. The data are not publicly available due to privacy or ethical restrictions. 


\section{REFERENCES}

Arnal, L.H., Giraud, A.L. (2012). Cortical oscillations and sensory predictions. Trends in cognitive sciences, 16(7), 390-398.

Baldoli, C., Scola, E., Della Rosa, P.A., Pontesilli, S., Longaretti, R., Poloniato, A., Scotti, R., Blasi, V., Cirillo, S., Iadanza, A., Rovelli, R., Barera, G., Scifo, P. (2015). Maturation of preterm newborn brains: a fMRI-DTI study of auditory processing of linguistic stimuli and white matter development. Brain Struct. Funct., 220(6): 3733-3751.

Bendixen, A., Schröger, E., Winkler, I. (2009). I heard that coming: event-related potential evidence for stimulus-driven prediction in the auditory system. J. Neurosci. 29, 8447-8451.

Bendixen, A., SanMiguel, I., Schröger, E. (2012). Early electrophysiological indicators for predictive processing in audition: a review. Int. J. Psychophysiol., 83, 120-131.

Bendixen, A., Scharinger, M., Strauss, A., Obleser, J. (2014). Prediction in the service of comprehension: Modulated early brain responses to omitted speech segments. Cortex, 53, 926.

Benitez, V.L., Saffran, J.R. (2018). Predictable events enhance word learning in toddlers. Cur. Biol., 28(17), 2787-2793.

Benjamini, Y., Hochberg, Y. (1995). Controlling the false discovery rate: a practical and powerful approach to multiple testing. Journal of the Royal statistical society: series B (Methodological), 57(1), 289-300.

Bhutta, A.T., Cleves, M.A., Casey, P.H., Cradock, M.M., Anand, K.J.S. (2002). Cognitive and behavioral outcomes of school-aged children who were born preterm: a meta-analysis. JAMA, 288(6), 728-737.

Blencowe, H., Cousens, S., Oestergaard, M.Z., Chou, D., Moller, A.B., Narwal, R., Adler, A., Vera Garcia, C., Rohde, S., Say, L., Lawn, J.E. (2012). National, regional, and worldwide estimates of preterm birth rates in the year 2010 with time trends since 1990 for selected countries: a systematic analysis and implications. The Lancet, 379(9832), 2162-2172.

Boldin, A.M., Geiger, R., Emberson, L.L. (2018). The emergence of top-down, sensory prediction during learning in infancy: A comparison of full-term and preterm infants. Developmental psychobiology, 60(5), 544-556.

Bosch, L. (2011). Precursors to language in preterm infants: speech perception abilities in the first year of life. In O. Braddick, J.Atkinson \& G.M. Innocenti (Eds.), Progress in brain research (Vol. 189, pp. 239-257). Burlington, VT: Academic Press. 
Čeponienè, R., Lepistö, T., Soininen, M., Aronen, E., Alku, P., Näätänen, R. (2004). Event-related potentials associated with sound discrimination versus novelty detection in children. Psychophysiology, 41(1), 130-141.

Cheour, M., Ceponiene, R., Lehtokoski, A., Luuk, A., Allik, J., Alho, K., Näätänen, R. (1998). Development of language specific phoneme representations in the infant brain. Nat. Neurosci., 1(5): 351-353.

Chobert, J., François, C., Velay, J.L., Besson, M. (2012a). Twelve months of active musical training in 8-to 10-year-old children enhances the preattentive processing of syllabic duration and voice onset time. Cereb. Cortex, 24(4), 956-967.

Chobert, J., François, C., Habib, M., Besson, M. (2012b). Deficit in the preattentive processing of syllabic duration and VOT in children with dyslexia. Neuropsychologia, 50(8), 2044-2055.

Dehaene-Lambertz, G., Dehaene, S. (1994). Speed and cerebral correlates of syllable discrimination in infants. Nature, 370(6487), 292.

Dehaene-Lambertz, G., Baillet, S. (1998). A phonological representation in the infant brain. Neuroreport, 9(8), 1885-1888.

Dehaene-Lambertz, G., Peña, M. (2001). Electrophysiological evidence for automatic phonetic processing in neonates. Neuroreport, 12(14), 3155-3158.

Dehaene-Lambertz, G., Dehaene, S., Hertz-Pannier, L. (2002). Functional neuroimaging of speech perception in infants. Science, 298: 2013-2015.

Emberson, L.L., Boldin, A.M., Riccio, J.E., Guillet, R., Aslin, R.N. (2017). Deficits in topdown sensory prediction in infants at risk due to premature birth. Cur. Biol., 27(3), 431-436.

Figueras, M.M., Bosch, L.G. (2010). Phonetic discrimination ability of a native vowel contrast in preterm infants. Psicothema, 22(4), 669-676.

François, C., Teixidó, M., Takerkart, S., Agut, T., Bosch, L., Rodriguez-Fornells, A. (2017). Enhanced Neonatal Brain Responses To Sung Streams Predict Vocabulary Outcomes By Age 18 Months. Scientific reports, 7(1), 12451.

Friston, K. (2005). A theory of cortical responses. Philosophical transactions of the Royal Society B: Biological sciences, 360(1456), 815-836.

Gagnepain, P., Henson, R.N., Davis, M.H. (2012). Temporal predictive codes for spoken words in auditory cortex. Cur. Biol., 22, 615-621. 
Griffiths, S.K., Brown, W. S. Jr., Gerhardt, K.J., Abrams, R. M., Morris, R.J. (1994). The perception of speech sounds recorded within the uterus of a pregnant sheep. J. Acoust. Soc. Am., 96(4): 2055-2063.

Grisoni, L., Mohr, B., Pulvermüller, F. (2019). Prediction mechanisms in motor and auditory areas and their role in sound perception and language understanding. NeuroImage, 199, 206216.

Háden, G.P., Stefanics, G., Vestergaard, M.D., Denham, S.L., Sziller, I., Winkler, I. (2009). Timbre-independent extraction of pitch in newborn infants. Psychophysiology, 46(1), 69-74.

Háden, G.P., Németh, R., Török, M., Drávucz, S., Winkler, I. (2013). Context effects on processing widely deviant sounds in newborn infants. Front. Psychol., 4, 674.

Háden, G.P., Németh, R., Török, M., Winkler, I. (2015). Predictive processing of pitch trends in newborn infants. Brain research, 1626, 14-20.

Háden, G.P., Németh, R., Török, M., Winkler, I. (2016). Mismatch response (MMR) in neonates: Beyond refractoriness. Biol. psychol., 117, 26-31.

Herold, B., Höhle, B., Walch, E., Weber, T., Obladen, M. (2008). Impaired word stress pattern discrimination in very-low-birth weight infants during the first 6 months of life. Dev. Med. Child Neurol., 50, 678-683.

Hillenbrand, J., Gayvert, R.T. (1993). Vowel classification based on fundamental frequency and formant frequencies. J. Speech, Language, and Hearing Research, 36(4), 694-700.

Jansson-Verkasalo, E., Ruusuvirta, T., Huotilainen, M., Alku, P., Kushnerenko, E., Suominen, K., Rytky, S., Luotonen, M., Kaukola, T., Tolonen, U., Hallman, M. (2010). Atypical perceptual narrowing in prematurely born infants is associated with compromised language acquisition at 2 years of age. BMC neuroscience, 11(1), 88 .

Key, A. P., Lambert, E. W., Aschner, J. L., Maitre, N. L. (2012). Influence of gestational age and postnatal age on speech sound processing in NICU infants. Psychophysiol., 49(5), 720731.

Kostilainen, K., Wikström, V., Pakarinen, S., Videman, M., Karlsson, L., Keskinen, M., Scheinin, N.M., Karlsson, H., Huotilainen, M. (2018). Healthy full-term infants' brain responses to emotionally and linguistically relevant sounds using a multi-feature mismatch negativity (MMN) paradigm. Neuroscience letters, 670, 110-115.

Kushnerenko, E., Ceponiene, R., Balan, P., Fellman, V., Näätänen, R. (2002). Maturation of the auditory change detection response in infants: A longitudinal ERP study. Brain Imaging, 13(15): 1843-1848. 
Kushnerenko, E., Winkler, I., Horváth, J., Näätänen, R., Pavlov, I., Fellman, V., Huotilainen, M. (2007). Processing acoustic change and novelty in newborn infants. Eur. J. Neurosci., 26(1), 265-274.

Kushnerenko, E.V., Van den Bergh, B.R., Winkler, I. (2013). Separating acoustic deviance from novelty during the first year of life: a review of event-related potential evidence. Front. Psychology, 4, 595.

Lahav, A., Skoe, E. (2014). An acoustic gap between the NICU and womb: a potential risk for compromised neuroplasticity of the auditory system in preterm infants. Front. Neurosci., 8,381 .

Lecanuet, J.P., Schaal, B. (1996). Fetal sensory competencies. European Journal of Obstetrics \& Gynecology and Reproductive Biology, 68, 1-23.

Liu, Y., Balériaux, D., Kavec, M., Metens, T., Absil, J., Denolin, V., Pardou, A., Avni, F., Van Bogaert, P., Aeby, A. (2010). Structural asymmetries in motor and language networks in a population of healthy preterm neonates at term equivalent age: a diffusion tensor imaging and probabilistic tractography study. Neuroimage, 51(2): 783-738.

Lisker, L., Abramson, A.S. (1967). Some effects of context on voice onset time in English stops. Language and speech, 10(1), 1-28.

Mahmoudzadeh, M., Dehaene-Lambertz, G., Fournier, M., Kongolo, G., Goudjil, S., Dubois, J., Grebe, R., Wallois, F. (2013). Syllabic discrimination in premature human infants prior to complete formation of cortical layers. Proceedings of the National Academy of Sciences USA, 110(12), 4846-4851.

Mahmoudzadeh, M., Wallois, F., Kongolo, G., Goudjil, S., Dehaene-Lambertz, G. (2017). Functional Maps at the Onset of Auditory Inputs in Very Early Preterm Human Neonates. Cereb. Cortex, 27(4), 2500-2512.

Maitre, N.L., Lambert, W.E., Aschner, J.L., Key, A.P. (2013). Cortical speech sound differentiation in the neonatal intensive care unit predicts cognitive and language development in the first 2 years of life. Dev. Med. Child Neurol., 55(9): 834-849.

Martynova, O., Kirjavainen, J., Cheour, M. (2003). Mismatch negativity and late discriminative negativity in sleeping human newborns. Neuroscience Letters, 340(2), 75-78.

Mueller, J.L., Friederici, A.D., Männel, C. (2012). Auditory perception at the root of language learning. Proceedings of the National Academy of Sciences USA, 109(39), 15953-15958. 
Mürner-Lavanchy, I., Steinlin, M., Kiefer, C., Weisstanner, C., Ritter, B.C., Perrig, W., Everts, R. (2014). Delayed development of neural language organization in very preterm born children. Dev. Neuropsychol., 39(7), 529-542.

Näätänen, R., Pakarinen, S., Rinne, T., Takegata, R. (2004). The mismatch negativity (MMN): towards the optimal paradigm. Clin. Neurophysiol., 115(1), 140-144.

Näätänen, R., Paavilainen, P., Rinne, T., Alho, K. (2007). The Mismatch Negativity (MMN) in basic research of central auditory processing: a review. Clin. Neurophysiol., 118(12), 2544-2590.

Otte, R. A., Winkler, I., Braeken, M.A.K.A., Stekelenburg, J.J., Van der Stelt, O., Van den Bergh, B.R.H. (2013). Detecting violations of temporal regularities in waking and sleeping two-month-old infants. Biological Psychology, 92(2), 315-322.

Paquette, N., Vannasing, P., Tremblay, J., Lefebvre, F., Roy, M.S., McKerral, M., Lepore, F., Lassonde, M., Gallagher, A. (2015). Early electrophysiological markers of atypical language processing in prematurely born infants. Neuropsychologia, 79, 21-32.

Partanen, E., Pakarinen, S., Kujala, T., Huotilainen, M. (2013). Infants' brain responses for speech sound changes in fast multifeature MMN paradigm. Clin. Neurophysiol., 124(8), 1578-1585.

Peña, M., Pittaluga, E., Mehler, J. (2010). Language acquisition in premature and full-term infants. Proceedings of the National Academy of Sciences USA, 107, 3823-3828

Peña, M., Werker, J.F., Dehaene-Lambertz, G. (2012). Earlier speech exposure does not accelerate speech acquisition. J. Neurosci., 32(33), 11159-11163.

Phillips, H.N., Blenkmann, A., Hughes, L.E., Kochen, S., Bekinschtein, T.A., Rowe, J.B. (2016). Convergent evidence for hierarchical prediction networks from human electrocorticography and magnetoencephalography. Cortex, 82, 192-205.

Ragó, A., Honbolygó, F., Róna, Z., Beke, A., Csépe, V. (2014). Effect of maturation on suprasegmental speech processing in full-and preterm infants: a mismatch negativity study. Research in developmental disabilities, 35(1), 192-202.

Rivera-Gaxiola, M., Silva-Pereyra, J., Kuhl, P.K. (2005). Brain potentials to native and non native speech contrasts in 7- and 11-month-old American infants. Dev. Sci., 8(2), 162-172.

Sansavini, A., Guarini, A., Justice, L.M., Savini, S., Broccoli, S., Alessandroni, R., Faldella, G. (2010). Does preterm birth increase a child's risk for language impairment? Early hum. dev., 86(12), 765-772. 
Suppiej, A., Mento, G., Zanardo, V., Franzoi, M., Battistella, P.A., Ermani, M., Bisiacchi, P. S. (2010). Auditory processing during sleep in preterm infants: An event related potential study. Early human development, 86(12), 807-812.

Therien, J.M., Worwa, C.T., Mattia, F.R. (2004). Altered pathways for auditory discrimination and recognition memory in preterm infants. Dev. med. child neurol., 46(12), 816-824.

Vidal, Y., Brusini, P., Bonfieni, M., Mehler, J., Bekinschtein, T.A. (2019). Neural Signal to Violations of Abstract Rules Using Speech-Like Stimuli. eNeuro, 6(5).

Wacongne, C., Labyt, E., van Wassenhove, V., Bekinschtein, T., Naccache, L., Dehaene, S. (2011). Evidence for a hierarchy of predictions and prediction errors in human cortex. Proceedings of the National Academy of Sciences, 108(51), 20754-20759.

Werker, J.F., Hensch, T.K. (2015). Critical periods in speech perception: new directions. Annual review of psychology, 66.

Ylinen, S., Huuskonen, M., Mikkola, K., Saure, E., Sinkkonen, T., Paavilainen, P. (2016). Predictive coding of phonological rules in auditory cortex: A mismatch negativity study. Brain and language, 162, 72-80.

Ylinen, S., Bosseler, A., Junttila, K., Huotilainen, M. (2017). Predictive coding accelerates word recognition and learning in the early stages of language development. Developmental science, 20(6), 12472.

Zatorre, R.J., Belin, P. (2001). Spectral and temporal processing in human auditory cortex. Cereb. cortex, 11(10), 946-953.

Zhang, Y., Koerner, T., Miller, S., Grice-Patil, Z., Svec, A., Akbari, D., Tusler, L., Carney, E. (2011). Neural coding of formant-exaggerated speech in the infant brain. Dev. Sci., 14(3), $566-581$. 